\title{
Single-Visit Apexification of Immature Necrotic Permanent Teeth with the use of Mineral Trioxide Aggregate: A Case Series
}

\author{
Ishika Garg ${ }^{1}$ Anu Kadian' Ritu Namdev Arun Kumar ${ }^{1}$ \\ 'Department of Pedodontics and Preventive Dentistry, PGIDS, Rohtak, \\ Haryana, India \\ Address for correspondence: Anu Kadian, Department of \\ Pedodontics and Preventive Dentistry, PGIDS, Rohtak, Haryana, India \\ E-mail: anukadian@gmail.com
}

\begin{abstract}
The treatment of immature necrotic permanent teeth with wide open apices often poses a significant challenge for the clinician. The lack of an apical stop complicates the obturation and achievement of good apical seal in such teeth. The treatment of choice for necrotic teeth with immature root is apexification, which is induction of apical closure to produce more favorable conditions for conventional root canal filling. The most commonly advocated medicament is calcium hydroxide. But the disadvantages of long treatment time, tooth fracture risk and incomplete calcification of apical bridge have led to the development of newer biocompatible materials which can complete apexification in a single visit. Although different materials are available, Mineral Trioxide Aggregate (MTA) remains the material of choice for forming an immediate apical barrier because of its superior clinical properties and high success rate. This case series highlights the use of MTA for formation of hard tissue barrier in nonvital permanent teeth with open apices with demonstrated clinical and radiographic success.
\end{abstract}

Keywords: Apexification, apical barrier, immature permanent teeth, mineral trioxide aggregate (MTA), necrotic pulp

\section{Introduction}

Traumatic injuries to young permanent teeth are a relatively common occurrence during childhood affecting $30 \%$ of children. These injuries often result in inflammation or necrosis of pulp and subsequent incomplete development of root apices.[1] Such teeth present with widened root canals and open apices rendering the conventional endodontic treatment technically more difficult and time consuming.[2] Because of the lack of apical barrier to contain the root filling material, obturation of the root canal with an open apex is difficult. The treatment of choice in such cases is apexification, i.e., establishing an apical barrier.[3]
Apexification can be defined as a 'method to induce a calcified barrier in a root with an open apex or the continued apical development of teeth with incomplete roots and a necrotic pulp' (American Association of Endodontists 2003). Traditionally, calcium hydroxide $\mathrm{Ca}(\mathrm{OH})_{2}$ has been widely used for the apexification procedure due to its biological and healing performances. However, the average length of time taken by this material to form the hard tissue barrier ranges from 5-20 months[4] and may necessitate one or multiple monthly appointments to place it inside the root canal and achieve the elimination of the intracanal infection, which stimulates calcification and produces the apical closure.[5] It has also been shown that the use of calci-

How to cite this article: Garg I, Kadian A, Namdev R, Kumar A. Single-Visit Apexification of Immature Necrotic Permanent Teeth with the use of Mineral Trioxide Aggregate: A Case Series. J Pediatr Dent 2020;6(1):33-37 
um hydroxide weakens the resistance of the dentin to fracture and may alter the mechanical properties of dentin making these teeth more susceptible to root fracture.[6,7]

The traditional use of $\mathrm{Ca}(\mathrm{OH})_{2}$ is being gradually replaced by mineral trioxide aggregate (MTA) as a onestep apexification technique. $[8,9]$ MTA produces apical physical barrier with significantly greater consistency than calcium hydroxide.[10] A biocompatible material, MTA also helps in the formation of bone and periodontium around its interface.[11] A bonded restoration can then be placed without any delay, thus reducing the possibility of root fractures.[3] The clinical success of MTA for one-visit apexification procedure has been reported by many authors in the literature.

The present case series reports successful treatment of three immature permanent teeth with open apices wherein MTA was used for one-step apexification.

\section{Case Presentation}

\section{Case 1}

A 9 year old male patient reported with the chief complaint of pain in upper front tooth in the past 5 days. There was a history of trauma to the same tooth due to fall about one week back. The medical history of the patient was non-significant. Clinical examination revealed Ellis class 3 fracture in permanent maxillary right central incisor. The tooth did not demonstrate any abnormal mobility or sensitivity to percussion. Both cold and electric sensibility tests failed to elicit any response. Periapical radiograph showed incomplete root development with wide open apex for the same tooth (Fig. 1a). MTA apexification was planned as the treatment of choice. Informed written consent was obtained from the child's parents. After rubber dam isolation, the tooth 11 was accessed and working length was determined radiographically. The canal was irrigated with saline. Biomechanical preparation was carried out using International Organization for Standardization (ISO) $80 \mathrm{~K}$-file (Dentsply Maillefer, Switzerland) with circumferential filing motion. Thorough root canal debridement was done using alternative irrigation with copious amount of $2.5 \%$ sodium hypochlorite $(\mathrm{NaOCl})$ (Ammdent, India) and saline. A volume of $3 \mathrm{ml}$ of $17 \%$ ethylene diamine tetra acetic acid (EDTA) solution (Prevest Denpro, India) was used for smear layer removal. Calcium hydroxide (ApexCal medicament paste, Ivoclar Vivadent AG Schaan, Liechtenstein) was placed in the root canal as a disinfectant material and access cavity was restored with Cavit (3 M ESPE, Seefeld, Germany). The patient was recalled after 5 days. At subsequent appointment, the tooth 11 was again isolated with rubber dam and the root canal was irrigated with $2.5 \% \mathrm{NaOCl}$ (Ammdent, India) and 2\% chlorhexidine (Dentochlor, Ammdent, India) to remove any remnants of the calcium hydroxide medicament along with complete disinfection. The canal was dried with absorbent paper points (Meta BioMed, Korea) and White MTA Angelus (Angelus, Londrina, PR, Brazil) was mixed with distilled water according to the manufacturer's instructions and carried to the canal with an amalgam carrier. Apical plug of about $4 \mathrm{~mm}$ of MTA was placed and confirmed radiographically (Fig.1b). A sterile cotton pellet moistened with sterile water was placed over the canal orifice and the access cavity was sealed with Cavit ( 3 M ESPE, Seefeld, Germany). After $72 \mathrm{~h}$, the
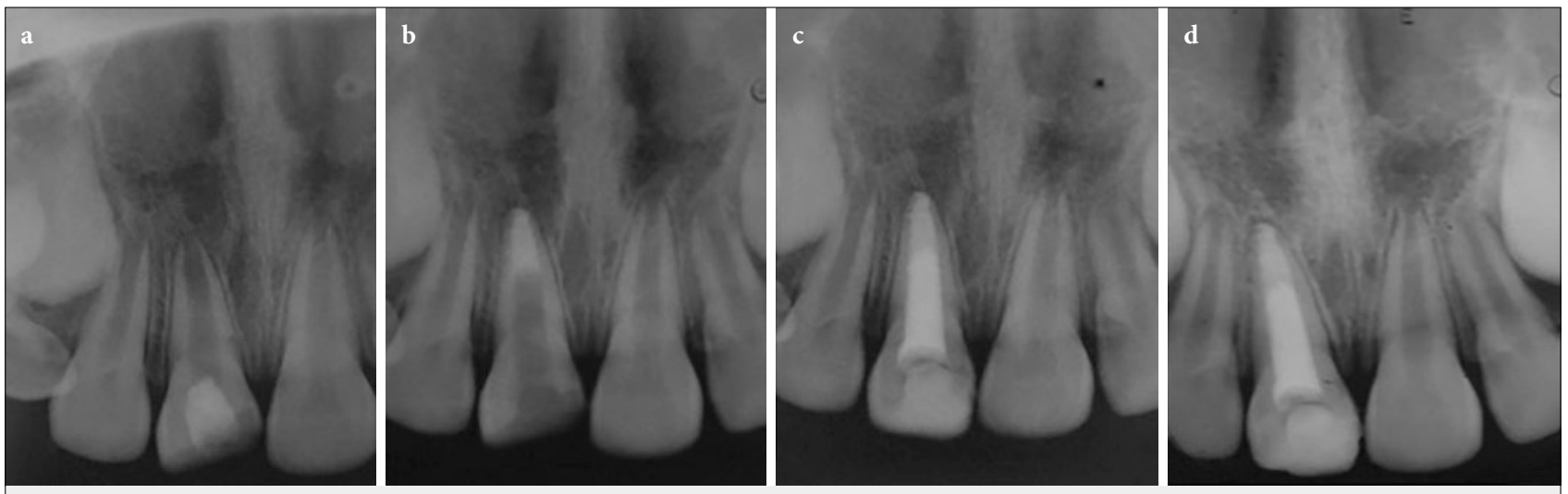

Figure 1. Case 1: Apexification in right maxillary central incisor using MTA (a) Pre-operative intra-oral periapical radiograph showing open apex in respect to tooth \#11. (b) MTA plug of 3-4 mm thickness was placed. (c) Post-obturation radiograph in respect to \#11. (d) Nine-months post-operative intra-oral periapical view showing resolution of the periapical lesion and induction of root end closure with new hard tissue formation over MTA 
hard set of MTA was confirmed and the remainder of the root canal was obturated with gutta-percha (Meta BioMed, Korea) and AH-Plus root canal sealer (Dentsply Detrey GMBH, Germany) using lateral condensation technique. The access cavity was sealed with glass ionomer cement (3M Espe Ketac Cem) followed by restoration of the tooth with Brilliant Ng resin restoration (Coltene/Whaledent, Switzerland) (Fig. 1c).

\section{Case 2}

A 10 year old male patient presented with the chief complaint of fractured upper front tooth with a history of trauma 1 year ago. The medical history was insignificant. Clinical examination revealed Ellis class III fracture in maxillary right central incisor and discolouration. The tooth was non tender on percussion with no mobility. The tooth did not respond to the pulp vitality tests. Radiographic examination demonstrated the presence of open apex with respect to tooth 11 (Fig. 2a). The available treatment options were discussed with the patient and root canal therapy using MTA as an apical barrier was selected and carried out as described above (Fig. 2b, 2c).
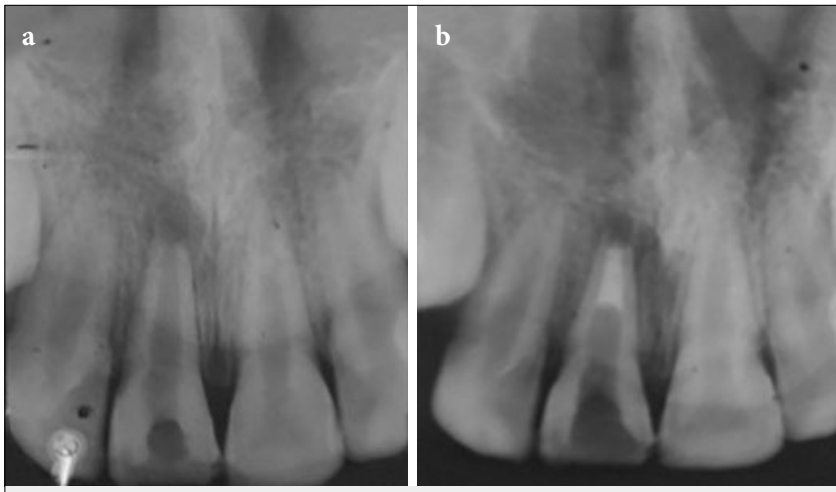

\section{Case 3}

A 10-year-old female patient presented with the chief complaint of severe pain in lower right back tooth since around 5 days ago. She had a history of root canal treatment initiated in the concerned tooth around 4 months back which was not completed. The medical history was insignificant. Clinical examination revealed opened access in right permanent mandibular second premolar with dislodged restoration. The tooth was tender on percussion and responded negatively to pulp vitality tests. Periapical radiograph showed incomplete root development with open apex in respect to tooth 45 (Fig. 3a). MTA apexification followed by root canal treatment was done in the concerned premolar as described in the above two cases followed by composite restoration (Fig. 2b, 2c).

After 9 months follow up period, the teeth in all the three cases remained healthy and asymptomatic clinically with normal mobility, probing depths, and normal function without symptoms. Radiographic resolution of the periapical lesion and induction of root end closure with new hard tissue formation over MTA was seen in all the three cases described in the present series. (Fig. $1 d, 2 d, 3 d)$.
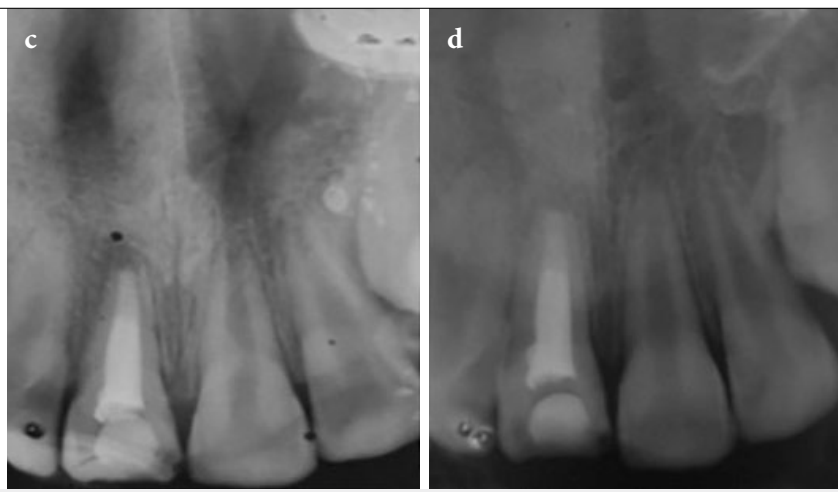

Figure 2. Case 2: Apexification in right maxillary central incisor using MTA (a) Pre-operative intra-oral periapical radiograph showing open apex in respect to tooth \#11. (b) MTA plug of 3-4 mm thickness was placed. (c) Post-obturation radiograph in respect to \#11. (d) Nine-months post-operative intra-oral periapical view showing resolution of the periapical lesion and induction of root end closure with new hard tissue formation over MTA
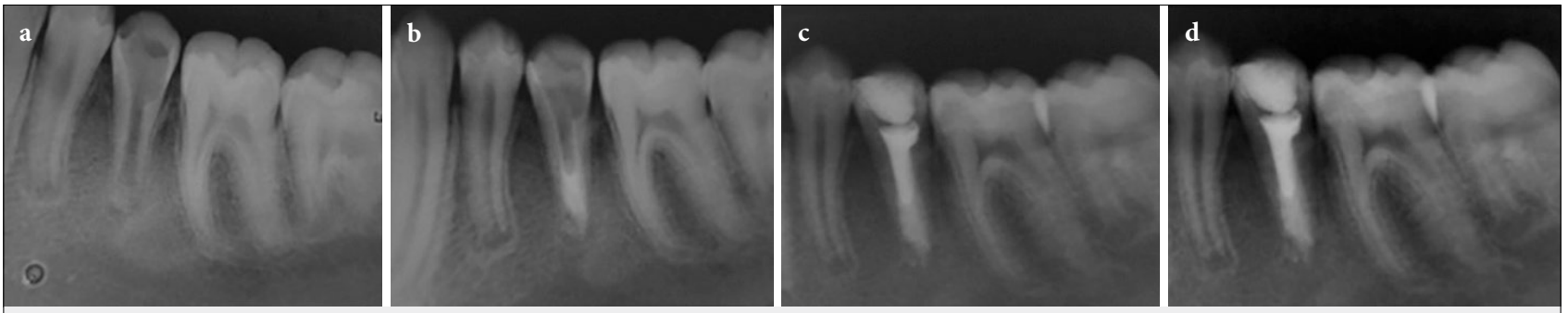

Figure 3. Case 3: Apexification in right mandibular second premolar using MTA (a) Pre-operative intra-oral periapical radiograph showing open apex in respect to tooth \#45. (b) MTA plug of 3-4 mm thickness was placed. (c) Post-obturation radiograph in respect to \#45. (d) Nine-months post-operative intra-oral periapical view showing resolution of the periapical lesion and induction of root end closure with new hard tissue formation over MTA 


\section{Discussion}

The goal of apexification procedure is to induce the formation of apical barrier to prevent the passage of toxins and bacteria into periapical tissues from root canal.[12] For many years, calcium hydroxide paste was used to induce a calcified barrier followed by root canal procedure. However, the conventional apexification material $\mathrm{Ca}(\mathrm{OH})_{2}$ has shown inherent disadvantages such as variability in treatment time, unpredictability of apical closure, difficulty in patient follow-up, failure in controlling infection, recurrence of infection, cervical fracture, and increased risk of root fracture. $[6,10,13]$ Single visit apexification using mineral trioxide aggregate (MTA) is a new boon in effective management of nonvital tooth with an open apex and has become the chosen material to induce the formation of the apical barrier because of its sealing properties and biocompatibility.

MTA is a promising alternative to calcium hydroxide. The material consists of fine hydrophilic particles of tricalcium silicate, silicate oxide and tricalcium oxide. The advantages of this material are (i) reduction in treatment time, (ii) immediate restoration of the tooth, (iii) no adverse effect on the mechanical properties of root dentin.[3] Several studies have demonstrated its capacity to induce odontoblastic differentiation, good radiopacity, low solubility, high $\mathrm{pH}$, expansion after setting, and antimicrobial activity.[5,14] The mechanism of action of this Portland cement lies in releasing calcium ions that activate cell attachment and proliferation, and at the same time, the high $\mathrm{pH}$ creates an antibacterial environment.[15] In a prospective study, MTA apexification showed a high prevalence of healing and apical closure.[16]

Complete disinfection of the root canal is mandatory before obturation. Root canals with open apices have more interaction with outside elements compared to completely closed apex. In the present case series, disinfection of the canals was done using $5.25 \% \mathrm{NaOCl}$ in all three cases and calcium hydroxide dressing was given as intracanal medication for periapical healing and eliminating the necrotic tissue remnants and bacterial byproducts after cleaning and shaping. Placement of MTA was done and condensed using Endodontic pluggers, followed by obturation.[17]

The thickness of MTA directly affects its hardness, sealing ability, and displacement when used as an apical barrier. In a study by Matt et al, a $5 \mathrm{~mm}$ thickness of MTA was found to be significantly stronger with less leakage than a $2 \mathrm{~mm}$ thickness.[18] A scientific article investigated displacement of MTA as an apical barrier material in teeth with open apices, showing that $4 \mathrm{~mm}$ thickness of the apical barrier offered significantly more resistance to displacement than $1 \mathrm{~mm}$ thickness.[19] Therefore, in accordance with the previous studies, $4-5 \mathrm{~mm}$ of MTA apical plug was placed in the present case series.

Aminoshariae et al demonstrated that manual condensation of MTA resulted in better adaptation with fewer voids than the ultrasonic method.[20] Accordingly, in the present case reports MTA placement and condensation was done manually with endodontic pluggers.

In a study by Maroto et al, successful apexification with MTA was reported in a tooth that did not respond favourably after 3 years of $\mathrm{Ca}(\mathrm{OH})_{2}$ therapy.[13] Kusgoz et al stated that MTA as a root end filling material is effective in immature necrotic pulpless teeth with shorter treatment time and better sealing ability.[17]

\section{Conclusion}

Single visit apexification with a novel biocompatible material like MTA has shown promising results as a root end filling material for effective management of teeth with wide open apices. This innovative procedure is predictable and less time consuming with a high overall success rate and good patient compliance.

\section{Financial Disclosure: Nil.}

Conflict of Interest: None declared.

\section{References}

1. Anantharaj A, Praveen P, Venkataraghavan K, Prathibha RS, Sudhir R, Murali Krishnan B. Challenges in pulpal treatment of young permanent teeth a review. J Dent Scien Res 2011;2:142

2. Moore A, Howley MF, O'Connell AC. Treatment of open apex teeth using two types of white mineral trioxide aggregate after initial dressing with calcium hydroxide in children. Dent Traumatol 2011;27(3):166-173

3. Purra AR, Ahangar FA, Chadgal S, Farooq R. Mineral trioxide aggregate apexification: A novel approach. J Conserv Dent 2016;19:377-380

4. Sheehy EC, Roberts GJ. Use of calcium hydroxide for apical barrier formation and healing in non-vital immature permanent teeth: A review. Br Dent J 1997;183:241-246

5. Nicoloso GF, Pötter IG, Rocha RO, Montagner F, Casagrande L. A comparative evaluation of endodontic treatments for immature necrotic permanent teeth based on clinical and radiographic outcomes: A systematic review and meta-analysis. Int J Paediatr Dent 2017;27:217-227

6. Andreasen JO, Farik B, Munksgaard EC. Long-term calcium hydroxide as a root canal dressing may increase risk of root fracture. Dent Traumatol 2002;18:134-137 
7. Iwaya S, Ikawa M, Kubota M. Revascularization of an immature permanent tooth with periradicular abscess after luxation. Dent Traumatol 2011;27:55-58

8. Purra AR, Ahangar FA, Chadgal S, Farooq R. Mineral trioxide aggregate apexification: A novel approach. J Conserv Dent 2016;19:377-380

9. Yadav P, Pruthi PJ, Naval RR, Talwar S, Verma M. Novel use of platelet-rich fibrin matrix and MTA as an apical barrier in the management of a failed revascularization case. Dent Traumatol $2015 ; 31: 328-331$

10. Shabahang S, Torabinejad M, Boyne PP, Abedi H, McMillan P. A comparative study of root-end induction using osteogenic protein-1, calcium hydroxide, and mineral trioxide aggregate in dogs. J Endod 1999;25:1-5

11. Torabinejad M, Pitt Ford TR, McKendry DJ, Abedi HR, Miller DA, Kariyawasam SP. Histologic assessment of mineral trioxide aggregate as a root-end filling in monkeys. J Endod 1997;23:225228

12. Kubasad GC, Ghivari SB. Apexification with apical plug of MTA-report of cases. Arch Oral Sci Res 2011;1:104-107

13. Maroto M, Barbería E, Planells P, Vera V. Treatment of a non-vital immature incisor with mineral trioxide aggregate (MTA). Dent Traumatol 2003;19:165-169
14. Parirokh M, Torabinejad M. Mineral trioxide aggregate: a comprehensive literature review-part III: clinical applications, drawbacks, and mechanism of action. J Endod 2010;36:400-413

15. Kratchman SI. Perforation repair and one-step apexification procedure. Dent Clin North Am 2004;48:291-307

16. Simon S, Rilliard F, Berdal A, Machtou P. The use of mineral trioxide aggregate in one-visit apexification treatment: a prospective study. Int Endod J 2007;40(3):186-197

17. Kusgoz A, Yildirim T, Tanriver M, Yesilyurt C. Treatment of horizontal root fractures using MTA as apical plug: report of 3 cases. Oral Surg Oral Med Oral Pathol Oral Radiol Endod 2009;107(5):e68-e72

18. Matt GD, Thorpe JR, Strother JM, McClanahan SB. Comparative study of white and gray Mineral Trioxide Aggregate (MTA) simulating a one- or two-step apical barrier technique. J Endod 2004; 30:876-879

19. Hachmeister DR, Schindler WG, Walker WA, Thomas DD. The sealing ability and retention characteristics of mineral trioxide aggregate in a model of apexification. J Endod 2002;28:386-390

20. Aminoshariae A, Hartwell GR, Moon PC. Placement of mineral trioxide aggregate using two different techniques. J Endod 2003; 29:679-682 